\title{
Produção coletiva da pessoa com deficiência: rastreando mediações
}

\section{Collective production of disabled people: tracking mediations}

\author{
1 Julio Cesar de Almeida Nobre julio.nobre@foa.org.br \\ 1 Ivanete da Rosa Silva de Oliveira \\ 2 Nathan da Cunha Gonçalves \\ 2 Joseane de Almeida dos Santos \\ 2 Camila Fernandes da Silva \\ 2 Dyene Kelly Leopoldina Rodrigues da Silva
}

1 Docente do Centro Universitário de Volta Redonda, UniFOA

\section{RESUMO}

A concepção de pessoa com deficiência tem se revelado instável no tempo. Na Grécia antiga, crianças com deformidades físicas eram descartadas. No início da Era Cristã, apesar da deficiência estar articulada com a noção de pecado, despontam práticas de acolhimento, como as ocorridas em hospitas cristãos. $\mathrm{Na}$ Inquisição, agravou-se a articulação com o pecado e concebeu-se a deficiência como relacionamento com o demônio. Nas Cruzadas, porém, muitos passaram a possuir corpos mutilados derivados de guerras santas, esvaziando tal articulação. Com as teorias newtonianas e a medicina moderna, o corpo passa a ser compreendido como mecanismo regido por leis universais. Assim, uma deficiência começa a se produzir como erro no equilíbrio da máquina, no qual normal e patológico são opostos a disputar o corpo, sendo tal normalidade um objeto de contornos anatomofisiológicos bem definidos. Na atualidade, encontramos diferentes cenários a envolver a pessoa com deficiência. No modelo médico, tal deficiência é tratada como anormalidade, com práticas de cura. No modelo da Integração Social, existe a intenção de integração ao social, porém gerando ambientes segregados que simulam o cotidiano. Já no modelo Inclusivista, o social também busca se adaptar no sentido de incluir o diferente. $E$ nesse cenário despontam controvérsias. Os modelos Médico e da Integração Social encontram-se superados? Utilizando-se do referencial da Teoria Ator-rede, objetiva-se analisar a controvertida rede que produz a "pessoa com deficiência" na atualidade, imbricada com mediadores diversos.

\section{Palavras-chave}

Inclusão. Pessoa com deficiência. Teoria ator-rede.

\begin{abstract}
The conception of disabled people has proved to be unstable in time. Inancient Greece, children with physical deformities were discarded. At the beginning of the Christian Era, although disability is articulated with thenotion of sin, reception practices, such as those occurring in Christian hospitals, emerge. In the Inquisition, the articulation with the sin was aggravated and the deficiency was conceived as a relationship with the devil. In the Crusades, however, many came to possess mutilated bodies derived from holy wars, emptying such articulation. With Newtonian theories and modern medicine, the body becomes understood as a mechanism governed by universal laws. Thus, a deficiency begins to occur as an error in the equilibrium of the machine, in which normal and pathological are oppositesto dispute the body, being such normality an object of well defined anatomo physiological contours. At present, we find different scenarios involving the disabled person. In the medical model, such deficiency istreated as an abnomality, with healing practices. In the model of Social Integration, there is the intention of integration to the social, but generating segregated environments that simulate everyday life. In the Inclusivist model, the social model also seeks to adapt to include the different. And in this scenario arise controversies. Are the Medical andSocial Integration models outdated? Using the Ator-Net Theory framework, the objective is to analyze the controversial network that produces the "personwith disabilities" today, interwoven with different mediators.
\end{abstract}

\section{Keywords}

Inclusion. Disabled person. Actor-network theory.

\section{Como você deve citar?}

NOBRE, Julio Cesar de Almeida et al. Produção coletiva da pessoa com deficiência: rastreando mediações. Cadernos UniFOA, Volta Redonda, n. 36 p. 55-68, abril. 2018. 


\section{INTRODUÇÃO}

Ao longo da história, o conceito de pessoa com deficiência tem se apresentado bastante variável e sido foco de intensas controvérsias. $\mathrm{Na}$ antiguidade, passamos por definições da pessoa com deficiência como seres humanos menores, em função de um ideal de corpo perfeito voltado para guerra ou para um perfil que serviria às demandas sociais articuladas às necessidades de aumento de poder e riqueza da nobreza, em detrimento de pessoas dotadas de marcas morfológicas concebidas como castigo divino.

Atualmente, a partir de uma concepção biomédica, é bastante comum uma abordagem que fixa seus pés em uma sólida normalidade entendida como um objeto de contornos anatomofisiológicos bem definidos. Desse modo, ainda parece ser significativa a concepção de pessoa com deficiência psíquica ou física articulada com termos como anomalia e invalidez.

Tal cenário nos leva a uma aproximação com a respectiva temática na busca de apreender um pouco melhor sobre tal realidade turbulenta e nos auxiliar a tecer como principal objetivo do presente estudo, portanto, analisar a controvertida rede que produz aquilo que se compreende por pessoa com deficiência na atualidade. Entendemos que tal concepção desponta de modo imbricado com argumentos acadêmicos, com políticas públicas, com a visibilidade produzida pela grande mídia, com o Direito, com os cidadãos comuns, etc.

Assim, para analisar tais controvérsias, utilizaremos o referencial teórico-metodológico da Teoria Ator-rede (LATOUR, 2008), isto é, rastrearemos as redes em ação, o trabalho de diversos mediadores a delinear pessoa com deficiência na justa medida das suas atuações. Assumiremos, então, uma posição simétrica em meio a argumentos e contra-argumentos, rastreando e descrevendo ações que são produzidas por tais mediadores.

\section{PESSOA COM DEFICIÊNCIA E ACESSIBILIDADE}

Desde a antiguidade, diversas são as abordagens acerca das pessoas que possuem alguma deficiência. Em muitas delas, pode-se encontrar a produção de tais pessoas articulada a conceitos como o de anomalia, invalidez e incapacidade.

Pereira (2009) discorre sobre o entendimento de deficiência, apresentando que essa concepção se produz, desde a história antiga até os dias atuais, por meio do distanciamento do que é considerado como "modelo homem-padrão" para atender às expectativas funcionais do social.

0 autor defende que, na Grécia antiga, por exemplo, a concepção de uma pessoa com deficiência era extremista, visto que a beleza era primordialmente um elemento indispensável e enaltecido, onde os indivíduos buscavam incessantemente à perfeição e quem não correspondesse a um padrão visual era eliminado. Em contrapartida, no Egito, tais pessoas chegavam a ser até mesmo divinizadas. $\mathrm{Na}$ antiga Palestina, estes eram articulados com elementos místicos, religiosos, sendo a deficiência considerada como uma marca no corpo, resultado de uma punição divina ou pecado cometido. Essa mesma concepção se perpetuou, influenciando o ocidente, desde a antiguidade até a atualidade, visto que, atualmente, muitas são as concepções de mundo que buscam interpretações através de elementos religiosos sobre a diferença funcional.

Embora no início da Era Cristã ainda tenha se mantido a relação entre pecado e deficiência, outras inciativas começaram a ser feitas por mosteiros. Hospitais cristãos primitivos passaram a acolher tais 
Julio Cesar de Almeida Nobre I Ivanete da Rosa Silva de Oliveira I Nathan da Cunha Gonçalves Joseane de Almeida dos Santos I Camila Fernandes da Silva I Dyene Kelly Leopoldina Rodrigues da Silva

indivíduos, assim como também orfanatos. Porém, muitas vezes, as pessoas acolhidas ainda conviviam com estigmas de pecadores (PEREIRA, 2009).

No decorrer da Idade Média, a influência da igreja estava no seu ápice e, articulada a ela, as pessoas com deficiência eram produzidas como manifestações demoníacas. Crianças com diferenças, físicas e mentais, compreendidas como fruto de uma união de uma mulher com o próprio demônio, eram lançadas a fogueiras junto com suas mães. Mais a frente, porém, uma nova concepção espiritual da igreja considera as pessoas com deficiência como filhos de Deus, levando à construção de casas de caridade e afrouxando os laços que imbricavam tais indivíduos com o mau trato e o abandono. Essa mudança de concepção surgiu com as Cruzadas, pois muitos eram aqueles que se viam mutilados na luta em prol da igreja. Seria, portanto, bastante contraditório afirmar que as deficiências de pessoas oriundas de defesas da própria igreja existiriam por motivos de pecado. Porém, salienta-se que, mesmo com uma atitude mais acolhedora da igreja, as pessoas com deficiência ainda continuaram a ser estigmatizadas como frutos de pecado.

Com a influência do antropocentrismo renascentista, no século XVI, a pessoa com deficiência passou a ser alvo de questionamentos acerca de sua origem sobrenatural. Pereira (2009) relata que o corpo passou a ser considerado como uma máquina, e as deficiências foram concebidas como disfunções de alguma parte, sendo objetivada como um desvio da normalidade. Cardano, médico e filósofo, e Paracelso, médico e alquimista, por exemplo, contribuíram para que tais quadros fossem analisados a partir de outros meios, considerados como mais objetivos e menos sobrenaturais. A medicina contribuiu muito para os avanços na concepção da pessoa com deficiência e as teorias de Isaac Newton foram bastante inovadoras.

Com a revolução industrial, no século XVIII, despontam novas articulações referentes à pessoa com deficiência que continuam sendo mediadas pela concepção do corpo que serve a alguém ou a algo. Com o modelo de produção das indústrias e o crescimento do capital, cresce a necessidade dos trabalhadores em acompanhar a demanda de trabalho. 0 novo modelo de produção valorizava o indivíduo através da sua capacidade em produzir e, consequentemente, essa nova relação de trabalho era bastante arredia a determinadas pessoas com deficiências, articulando-as com o estigma de invalidez. Essas condições excludentes foram reforçadas em décadas posteriores. 0 novo modelo de trabalho, com condições precárias, sem nenhum suporte de segurança e com jornadas longas, trazia acidentes frequentes, produzindo altos índices de acidentes e de pessoas com deficiência.

$\mathrm{Na}$ atualidade, quando direcionamos nossos pensamentos para o assunto da inclusão social da pessoa com deficiência (SASSAKI, 2010), pode-se verificar que o movimento de inclusão iniciou-se na segunda metade dos anos 80 , e tomou impulso na década de 90 . Salienta-se que se pode observar um fortalecimento ainda maior nos primeiros 10 anos do século 21 . 0 movimento inclusivista tem por objetivo a produção de uma realidade sem exclusão social. De acordo com Sassaki (2010), a menção da ótica inclusivista é algo novo na literatura especializada, mesmo sabendo-se que suas raízes nos remetem ao passado. Surgiram gradativamente, a partir de ideias que o autor chama de pré-inclusivista, no qual estão contidos os modelos médico da deficiência e da integração social.

Segundo Sassaki (2010), o modelo médico da deficiência demonstra sua persistência na atualidade, por meio de uma intensa resistência em relação à receptividade da necessidade de mudança, tanto nas atitudes quanto nas estruturas físicas, para inserir indivíduos com deficiência no dia a dia. De acordo com tal modelo, o social não precisa se adequar ao indivíduo. A pessoa com deficiência, entendida como inválida, deveria ser reabilitada, mudar seus padrões, tão somente adaptando-se ao coletivo. 
No que diz respeito ao modelo da integração social, busca-se confrontar o estigma da invalidez, por meio de duas estratégias: a Normatização e o Mainstreaming. A Normatização tem por alicerce a formação de locais similares àqueles povoados pelos cidadãos em geral, ao passo em que a ação do Mainstreaming equivale à integração propriamente dita, visando levar as pessoas com deficiência a utilizarem os serviços disponíveis na corrente principal da comunidade. Assim, segundo Sassaki (2010), a prática da integração social levou a inserção de pessoas com deficiências em locais isolados dentro dos sistemas gerais, como colégios especiais, turmas especiais em colégios comuns, etc, produzindo, desse modo, outra forma de segregação.

Já na atitude inclusivista, segundo Sassaki (2010), temos uma articulação da pessoa com deficiência com as noções de empoderamento, independência e autonomia ${ }^{3}$. 0 modelo inclusivista diz respeito a um modo pelo qual o social se adequa para ser capaz de incluir as diferenças. Estas, por sua vez, coincidentemente, encarregam-se igualmente de responder ao ambiente. Temos uma relação bilateral.

Diante desse cenário, muitas são as controvérsias e contradições articuladas à questão da inclusão da pessoa com deficiência. Segundo Araújo e Ferraz (2010, p. 8846), na busca da inclusão, "as normas existem, e em quantidade razoável, o que deve ser aferido é a higidez de sua efetivação". Os referidos autores argumentam que o empresariado brasileiro denuncia um excesso de regulação estatal nas questões trabalhistas. Um foco importante de controvérsia é a contratação compulsória de pessoas com deficiência, visto que forte é a crítica acerca da intervenção do Estado como um fator a desvirtuar a lógica natural da gestão.

\begin{abstract}
Adentrando a seara da inclusão social da pessoa com deficiência no mercado de trabalho têm-se duas ações afirmativas, que se consideram mais importantes, (...) Uma delas atua na esfera pública e é a reserva legal de vagas para pessoas com deficiência nos concursos públicos. Tal obrigatoriedade já possuía esteio constitucional no artigo 37, inciso VII. A segunda se destina a iniciativa privada e está inserida na lei geral da previdência social, embora tenha caráter nitidamente trabalhista. Trata-se do artigo 93 da Lei 8.213/91. (...) A ação afirmativa ora apresentada é a que manifesta maiores polêmicas na seara judicial e doutrinária (ARAÚJO; FERRAZ, 2010, p. 8850).
\end{abstract}

Por outro lado, argumenta-se que o poder das empresas em termos de capital mantém forte influência sobre as relações contratuais de trabalho, estabelecendo uma relação desigual. Daí a necessidade de legislações.

Araújo e Ferraz (2010) argumentam que existe um intenso preconceito diante da capacidade produtiva de pessoas com deficiência.

\footnotetext{
(...) situações de conflito com as quais se depara o Auditor Fiscal: a) a crença por parte da empresa na falta de habilidade da pessoa com deficiência para exercer determinadas atividades; b) o suposto risco de acidentes ou doenças ocupacionais a que estaria exposto o trabalhador e c) a ausência de trabalhadores qualificados no mercado (ARAÚJO; FERRAZ, 2010, p. 8851).
}

Por outro lado, apontam que os argumentos acerca de falta de capacidade laboral fortemente estão articulados com ausência de uma intenção real de adaptação da realidade às diferenças das pessoas com deficiência. Apontam, ainda, que a tecnologia poderia ser um fator decisivo nesse sentido. Em relação ao risco de acidentes, os autores argumentam que a segurança do trabalhador não é uma questão inerente, apenas, a pessoas com deficiência. Deve, portanto, ser uma preocupação constante das empresas, não cabendo desqualificar uma pessoa com deficiência por esse motivo.

3 A autonomia entendida como a possibilidade de domínio no ambiente físico e social, a independência enquanto a capacidade decisória sem depender dos outros e o empoderamento enquanto um processo de utilização do poder pessoal inerente à sua condição. 
Julio Cesar de Almeida Nobre I Ivanete da Rosa Silva de Oliveira I Nathan da Cunha Gonçalves Joseane de Almeida dos Santos I Camila Fernandes da Silva I Dyene Kelly Leopoldina Rodrigues da Silva

Podemos observar, diante do exposto, que existem significativas controvérsias na questão da pessoa com deficiência. Poderíamos afirmar que estamos em uma realidade na qual tais pessoas adquirem potência? Tendo por base o referencial da Teoria Ator-rede, buscaremos realizar uma análise da controvertida rede que produz aquilo que se entende por "pessoa com deficiência" na atualidade, bem como buscar identificar as múltiplas imbricações com possíveis mediadores dessa concepção.

\section{A TEORIA ATOR-REDE E O RASTREAMENTO DE COLETIVOS: UMA METODOLOGIA}

A Teoria Ator-rede - TAR é o estudo da construção das realidades a partir de um olhar sociotécnico, isto é, levando em consideração ciência, tecnologia e sociedade. Tendo como principais teóricos Bruno Latour e John Law, entre outros, diferentemente da crença da existência de uma verdade transcendental, a TAR argumenta pela necessidade do rastreamento dos processos de produção dos fatos, da imanente realidade. Essa produção, portanto, se dá por meio de traduções/mediações, isto é, os diferentes modos em que a existência circula nas redes.

A circulação nas redes, portanto, se dá através dos mediadores. Segundo Nobre e Pedro (2010, p. 48), "todo mediador é entendido, aqui, como seres/agenciamentos que não são nem puros humanos e nem puros não-humanos. Latour os denomina actantes". Assim, a TAR considera não só os humanos como criadores da realidade, mas também os não humanos (máquinas, legislação, objetos, etc). Em outras palavras, o que os humanos produzem também os produz. Dessa forma, nenhuma realidade é natural, por mais sólida que pareça. Ela é resultado das ações dos mediadores que a fazem circular. As verdades são produzidas por meio de um coletivo em ação.

Porém, em algum momento, realidades são consideradas como verdades inquestionáveis, formando assim o que Latour (2000) chama de caixa-preta, que seria um fato que se produziu como um sólido, que parece independente e autônomo. Ela começa a ser formada na ausência de controvérsia e se solidifica cada vez que é passada adiante como pressuposto tácito. Temos aqui um coletivo, uma estável rede de mediadores. A controvérsia tem a possibilidade de abrir uma caixa-preta, instabilizá-la, de explicitar aliados que se juntaram para formá-la, demonstrando que ela não é atemporal. Redes instáveis, que possuem controvérsias em discussão, são chamadas de caixa-cinza.

A discussão e a controvérsia estão imbricadas com a existência de grupos e antigrupos, ou seja, aliados articulados contra ou a favor de ideias ou fatos, os de "dentro" e os de "fora". Formam-se, assim, fronteiras, nas quais "muitos são os aliados trazidos para a defesa dos limites grupais. Ciência, filosofia, religiões, leis, tecnologias, etc. A existência de um grupo depende sempre de um constante trabalho" (NOBRE; PEDRO, 2010, p. 50). Com o acirramento da controvérsia, cada grupo necessitará mobilizar mais actantes para defender seus argumentos. Vemos aqui, portanto, redes que se estendem mobilizando pessoas, máquinas, tecnologias, leis, filosofias, ciências, religiões, etc.

No meio dessas batalhas, a TAR procura rastrear o trabalho dos mediadores, descrevendo suas mediações, analisando o que cada argumento mobiliza e como determinada verdade foi, ou está sendo, produzida. Para analisar as controvérsias, portanto, é preciso assumir uma posição simétrica em meio às discussões, não tomando partido de nenhum grupo. 0 objetivo, portanto, é seguir o trabalho dos mediadores diversos e, desse modo, descrever a produção coletiva de um fato na justa medida dos deslocamentos, na qual não se acrescenta nenhum fundamento ou teoria, nenhuma dimensão mais profunda de explicação, nenhuma tridimensionalidade. A ideia é seguir o terreno plano dos mediadores e descrever seus trabalhos. 
Bruno Latour (2000) salienta que os ordenamentos de uma rede seguem um direcionamento no sentido de se tornarem estáveis e adquirirem solidez. Desse modo, cada rede possui porta-vozes que precisam mobilizar aliados diversos. Existe um poder articulado a cada rede, um elemento de coerção. Nas brechas da coerção se dão as possibilidades de abertura e criação, nas quais entram os conceitos de Recalcitrância, aquilo que resiste ao ordenamento, e Plasma, o que ainda não está conectado às redes, "não é um fora do mundo, mas uma presença muda" (NOBRE; PEDRO, 2010, p. 52). Ambos representam brechas da coerção.

Redes, portanto, são dinâmicas. A aparente solidez "nada mais é que um efeito de um alinhamento de aliados, articulados na defesa de um argumento" (NOBRE; PEDRO, 2010, p. 50). A Teoria Ator-rede busca esses alinhamentos, dá voz aos mediadores e rastreia esses ordenamentos não para representar a realidade, uma suposta verdade a ser delineada, mas para descrever seus processos produtivos.

Desse modo, o presente trabalho busca rastrear a produção das fronteiras daquilo que se entende por pessoa com deficiência na atualidade. Diante do exposto, consideramos a TAR como um potente referencial teórico-metodológico e significativo aliado no estudo de instáveis coletivos. Sendo assim, apoiados em tal metodologia bastante minimalista, elegemos como porta de entrada em tais coletivos o material impresso encontrado na web, mais especificamente, trazidos pela grande mídia, visto que entendemos tais mediadores como muito significativos em seu poder de reverberação social.

\title{
4 RASTREANDO CONTROVÉRSIAS A ENVOLVER A PESSOA COM DEFICIÊNCIA E A ACESSIBILIDADE
}

As novas possibilidades sociais e legais que as pessoas com deficiência têm alcançado nos últimos anos no Brasil, como a Lei n 13.146/2015, Lei Brasileira de Inclusão da Pessoa com Deficiência (BRASIL, 2015), que entrou em vigor no referido ano e gerou o Estatuto da Pessoa com Deficiência, parecem apontar para a construção da PCD enquanto sujeito de direitos. A deputada Mara Gabrilli, relatora da proposta da respectiva lei, trouxe em destaque realmente esse aspecto:

\begin{abstract}
É um ganho para o Brasil, tanto para o segmento da pessoa com deficiência como para toda a população. Ao promover esse protagonismo da pessoa com deficiência no Brasil, você acaba alavancando todos os setores, já que a lei dispõe sobre trabalho, saúde, educação e sobre infraestrutura das cidades (CÂMARA NOTíCIAS, 2016).
\end{abstract}

O Senador Paulo Paim, em sintonia com a respectiva deputada, traz o Estatuto como uma afirmação de cidadania:

O Estatuto avança na cidadania dessas pessoas ao tratar de questões relacionadas à acessibilidade, educação, trabalho e do combate aos preconceitos e discriminação da pessoa com deficiência (SENADO NOTíCIAS, 2016).

Por outro lado, em uma matéria publicada na Revista Exame (2012), vemos uma argumentação sobre a já presente reverberação dos respectivos direitos nos meios de comunicação e no discurso do Estado, porém, ainda, sem efetivação.

\footnotetext{
Os direitos das pessoas com deficiência finalmente estão chegando aos meios de comunicação e sendo integrados ao discurso do Estado, mas as mudanças concretas de efetivação de cidadania ainda ocorrem de maneira lenta, diz a superintendente do Instituto Brasileiro dos Direitos de Pessoas com Deficiência (IBDD), Teresa d'Amaral (LEITÃO, 2012).
}

Quando rastreamos com maior cuidado o trabalho de mediadores diversos, encontramos dados que reforçam a visão da PCD como alvo de marginalização, bem como de intensas contradições. Na mídia internacional, números argumentam nesse sentido. Segundo matéria do The Independent, 
Julio Cesar de Almeida Nobre I Ivanete da Rosa Silva de Oliveira I Nathan da Cunha Gonçalves Joseane de Almeida dos Santos / Camila Fernandes da Silva I Dyene Kelly Leopoldina Rodrigues da Silva

de $08 / 11 / 2015$, o crime de ódio contra pessoas com deficiência aumentou $41 \%$ no período $2014-15$ (MORTIMER, 2015). Nessa matéria, Stephen Brookes, da Disability Hate Crime Network, traz as estatísticas como aliada de seu argumento, quando afirma que há cerca de 60.000 casos de crime de ódio contra pessoas com deficiência por ano, considerando, inclusive, que o número pode ser maior, visto que muitas pessoas ainda não denunciam esses crimes. Em sintonia com tal argumento, uma matéria do The Guardian, de 16/09/2011, aponta que $66 \%$ das pessoas com deficiência disseram já ter vivido "agressão, hostilidade ou xingamentos" (MARSH, 2011).

Indo para a mídia nacional, em uma matéria mais antiga, do Estadão, de 14/12/2010, tem-se uma pesquisa feita pelo DataSenado que afırma que $77 \%$ dos portadores de deficiência se sentem desrespeitados; na fala de Teresa Costa D'Amaral, superintendente do IDBB (Instituto Brasileiro dos Direitos da Pessoa Com Deficiência), "o preconceito ficou tão natural, como quando um deficiente físico é carregado para entrar no ônibus que não tem elevador, que as pessoas não percebem como preconceito" (THOMÉ, 2010). As principais queixas das PCD entrevistadas pela pesquisa dizem respeito à ausência de ações firmes do Estado, como, por exemplo, no transporte público: $43 \%$ dos entrevistados são usuários dos transportes públicos de suas cidades e $51 \%$ afirma que o problema é a falta de veículos adaptados. A acessibilidade nas ruas e calçadas também surgiu como grande entrave ao direito de ir e vir dessas pessoas, visto que $87 \%$ disseram que "nenhuma ou poucas das ruas estão adaptadas em sua cidade" (THOMÉ, 2010).

Uma matéria de $O$ Globo, de 17/09/2016, acerca da PCD no mercado de trabalho, afirma que, no ano de 2015 , houve um aumento de $32 \%$ nos postos de trabalho para pessoas com deficiência (SOUTO, 2016). Entretanto, apesar de existir uma cota de $2 \%$ a $5 \%$ de vagas para PCD em empresas acima de 100 funcionários, no ano de 2015, foram 4,5 mil autuações da fiscalização do Ministério do Trabalho sobre empresas que não cumprem essas cotas (SOUTO, 2016).

Quando o Estatuto da Pessoa com Deficiência ainda tramitava na Câmara dos Deputados como Projeto de Lei 7699/06, muitas eram as controvérsias já existentes no âmbito da PCD. Diversas entidades já se manifestavam contra a aprovação do texto. Curiosamente encontravam-se pessoas com deficiência contra o próprio Estatuto. Um movimento denominado como Movimento Nacional pela Constituição e Contra o Estatuto alegava que um Estatuto já seria a Constituição Federal do país, uma vez que já existiriam leis que garantiriam os direitos das PCD, bem como de qualquer outro cidadão. Alegavam que seria preciso, apenas, que as leis fossem cumpridas. "O estatuto das pessoas com deficiência é a Constituição, diz indignado Andrei" (MOURA, 2011). Andrei Bastos, Assessor da Superintendência do Instituto Brasileiro dos Direitos da Pessoa com Deficiência (IBDD), que faz parte do Movimento Nacional contra o Estatuto, conta que, quando soube do documento, chegou a pensar que seria bom. Porém, no trecho sobre acessibilidade, viu se tratar de um documento que beneficiaria as empresas de ônibus. Podemos perceber, nos argumentos de Andrei, que o respectivo Estatuto não está sendo traduzido como um instrumento a focalizar políticas afirmativas que garantiriam a inclusão social e a cidadania da PCD, mas como uma forma de favorecimento a terceiros, principalmente a setores privados, como o de transportes.

Os argumentos de Andrei parecem se articular com a redação da Lei 10.754 que altera a Lei 8.989:

Dispõe sobre a Isenção do Imposto sobre Produtos Industrializados - IPI, na aquisição de automóveis para utilização no transporte autônomo de passageiros, bem como por pessoas portadoras de deficiência física, e dá outras providências (BRASIL, 2003).

Nesse trecho, vemos que tal normatização pode facilitar o acesso da PCD ao veículo próprio, porém há uma ambiguidade nas políticas afirmativas criadas, que beneficiam não somente o deficiente, mas também as grandes empresas. 
Em matéria do G1, de 2015, encontramos outro foco de controvérsias legais acerca da acessibilidade de PCD. As tensões residiam, no caso, sobre a lei que estabelece que as cooperativas de táxis de Teresina deveriam possuir uma cota para veículos adaptados para pessoas com deficiência física. A Cooperativa de Taxistas de Teresina não viu atrativos para a categoria. De acordo com o presidente da cooperativa, Pedro Henrique Ferreira, a aquisição de um carro adaptado é cerca de $50 \%$ mais cara do que a de um veículo comum.

\begin{abstract}
Sancionada pelo prefeito Firmino Filho (PSDB), de autoria do vereador Antonio Aguiar (PROS) e aprovada por unanimidade na Câmara de Vereadores (...) a lei de número 4.678/2015 estabelece que $2 \%$ da frota de táxis em Teresina seja adaptada para deficientes físicos. (...) Mas de acordo com o presidente da cooperativa de taxistas de Teresina (...) a medida não é atrativa porque o custo de um carro adaptado é maior e que as concessionárias da capital não ofertam carros deste tipo. (...) Para ele, o projeto beneficiará os cadeirantes, mas não há vantagem para o taxista $(\mathrm{G1}, 2015)$.
\end{abstract}

$\mathrm{Na}$ análise dessa matéria, podemos verificar os objetivos financeiros colocados em questão: a proposta social da legislação, buscando uma inclusão da PCD, em conflito com interesses das empresas de transporte. Parece que tais mediadores produzem uma realidade cujos direitos da PCD são benefícios que acabariam por prejudicar os demais.

Outro foco de controvérsia encontrado seria em relação às vagas reservadas para PCDs em concursos públicos.

As vagas para as pessoas portadoras de deficiência em concurso público suscitam preocupações dos órgãos
governamentais realizadores dos certames, os representantes dos ministérios públicos no papel de fiscalizadores
e os concorrentes interessados. (...) Vários concursos foram suspensos em sede de liminar na Justiça face às
controvérsias existentes, pelo que deveria adotar um critério razoável e equilibrado para todos (CABRAL, 2010).

0 autor afırma que a legislação federal prevê uma cota mínima de $5 \%$ de vagas em concursos como atendimento da política nacional de integração dos portadores de deficiências físicas. Entretanto, caberia aos estados, distrito federal e municípios a regulamentação em lei própria. Não havendo tal regulamentação, estes devem adotar o percentual mínimo estipulado. Cabral, entretanto, afirma a necessidade de um critério justo no cálculo das respectivas vagas, visando não violar direitos como a universalidade e a isonomia dos candidatos (CABRAL, 2010).

Art. 37. A administração pública direta e indireta de qualquer dos Poderes da União, dos Estados, do Distrito Federal e dos Municípios obedecerá aos princípios de legalidade, impessoalidade, moralidade, publicidade e eficiência e, também, ao seguinte: VIII - a lei reservará percentual dos cargos e empregos públicos para as pessoas portadoras de deficiência e definirá os critérios de sua admissão (BRASIL, 1988).

Se a Constituição Federal, por um lado, em seu artigo n 37, traduz a PCD como dotada de direito de um percentual de vagas para cargos e empregos públicos, por outro, tais vagas ainda são motivos de grandes polêmicas que transformam tais pessoas com deficiência em alvos de discórdia. Vemos traduções que parecem argumentar por um contexto que fere a meritocracia.

Quando olhamos para os ambientes virtuais, a situação de preconceito parece se aprofundar. Se na vida cotidiana insinua uma significativa coerção que produz certo comportamento ainda respeitoso com os outros, mesmo que superficial, o mundo digital sugere um escape dessa coerção. 0 Huffington Post, de 21/08/2017, levanta a questão de levarmos a sério os crimes online da mesma forma que consideramos os off-line (SNOWDON, 2017). A matéria argumenta que os crimes online afetam a vida e a saúde mental das vítimas. Considerá-los menos perigosos que os crimes off-line seria um erro, porque o ódio no ambiente virtual recebe eco, pode gerar aplausos ao usuário que destila raiva (PEREIRA, 2017). Para o psicanalista Contardo Calligris, entrevistado pela BBC Brasil, em matéria publicada em 10/01/2017, 
Julio Cesar de Almeida Nobre I Ivanete da Rosa Silva de Oliveira I Nathan da Cunha Gonçalves Joseane de Almeida dos Santos I Camila Fernandes da Silva I Dyene Kelly Leopoldina Rodrigues da Silva

nas redes sociais, é possível expressar o seu ódio, dar a ele uma dimensão pública, receber aplausos pelos seus amigos e seguidores, e se sentir de alguma coisa validado. Ou seja, as redes sociais produzem uma espécie de validação do seu ódio que era muito mais difícil antes de elas existirem e se tornarem tão importantes na vida das pessoas (PEREIRA, 2017).

O psicanalista argumenta que esse tipo de comportamento "é algo que deveria ser perseguido, deveríamos ter limites claros ao que é o campo da liberdade de expressão, que é intocável, e o momento em que aquilo se torna uma ameaça" (PEREIRA, 2017). Em uma atualidade de instabilidade, onde várias caixas-pretas se abrem e trazem questões sobre o limite entre liberdade de expressão e discurso de ódio, as controvérsias referentes à pessoa com deficiência parecem ser facilmente visualizáveis na internet.

$\mathrm{Na}$ comunidade de jogos online, por exemplo, as piadas com deficiência têm se tornado comum. Um jogador de League of Legends (Riot Games, 2009) identificado como IviF, autista, publicou, no fórum público do site do jogo, uma postagem sobre ser autista e jogar LoL. Com o título de "A vantagem de ser autista no League of Legends", a postagem recebeu, até o momento, 228 reações positivas. No início do texto, IviF demonstra se sentir mal sobre o uso do autismo como piada para jogadores que cometem erros ou tem uma certa demora numa jogada. Ele lamenta que, inclusive, jogadores profissionais continuem a perpetuar o estigma do autista enquanto lento e não comunicativo com a equipe. E esses jogadores profissionais são porta-vozes de uma rede que, em 2016, movimentou RS 5,65 bilhões de reais e possuía 94,3 milhões de usuários mensais (ROX, 2016). Mas IviF argumenta que ser um autista num jogo online não é de todo ruim: "uma característica dos autistas é que quando eles se interessam por uma coisa, eles pesquisam a fundo a essa coisa; o que aconteceu comigo no LoL, eu pesquiso, leio, assisto vídeo de $1 \mathrm{~h}$ do cara explicando matchups, dicas e tudo mais" (IVIF, 2017). Além disso, ele expõe que o jogo tem proporcionado melhoras significativas para ele.

No LoL, como um jogo adaptativo, eu tô aprendendo a lidar melhor com mudanças, antes se mudasse minha roupa de lugar eu não usava. O LoL me ensina a ter empatia, quando alguém tá jogando mal eu tento ajudar, porque vai que ele não é ruim e sim só está tendo um dia ruim? O LoL me deu muitos amigos que conheço na vida real e tá melhorando muito minha interação social. Além de claro, ser um jogo bem desafiador e divertido. (IVIF, 2017).

Num momento onde a representatividade parece ser um tanto importante na questão da PCD, a série de livros A Song of Ice and Fire, de George R. R. Martin (adaptada para televisão pela HBO na série Game of Thrones), traz um elemento significativo: um personagem com nanismo como um dos protagonistas, Tyrion Lannister (interpretado no seriado por Peter Dinklage). Nesse contexto, um usuário do site de mídia social Reddit, FaceofMe, também com nanismo, escreveu um texto em um fórum público comentando sobre ser um anão e sua experiência ao ler o livro de Martin. Em um determinado momento, ele escreve uma trajetória das perspectivas sobre o nanismo:

A verdade é esta: ser um anão é carregar um peso de certas concepções culturais preconcebidas sobre o nanismo: $\mathrm{O}$ anão como depravado sexual, um Imp conspirador movido pelo prazer e um desejo bruto de possuir e destruir a beleza. $\mathrm{O}$ anão como a figura trágica, a piada cruel de deus, uma criatura digna de pena que pode encontrar alguma espécie de vingança no terceiro ato. 0 anão cômico, o duende feliz que espalha alegria e alivia tensões dramáticas, mágico e assexuado, talvez oferecendo encorajamento e inspiração se necessários (BINI, 2014).

Mais adiante, ao comentar sobre Tyrion, percebemos que o personagem fez o autor adquirir potência:

Eu não sou nenhum Tyrion (...). Nós, porém, compartilhamos várias coisas. Eu também encontrei uma espécie de paz ao abraçar papéis que os outros forçam a mim. Se vou ser escalado como o bobo, então vou fazer o papel o melhor possível. (...). Tyrion como personagem me fez entender melhor ser um anão, e apreciar mais completamente o valor único disto como uma experiência. Ele me ensinou a apreciar melhor meus dons, e a cultivá-los. Para melhor ou para pior, minha deficiência domina quem eu sou. Eu sou um anão. Eu vou fazer o papel o melhor que posso, aproveitar cada caprichoso minuto, e montar meu cão ao pôr do sol (BINI, 2014) 
Vivemos, assim, um momento de intensas controvérsias. Parece que a existência de leis, apesar de configurarem significativo avanço, por si só não têm garantido a inclusão e o combate ao preconceito contra a PCD. A estabilidade do discurso de respeito às diferenças é constantemente posta à prova.

No âmbito da propaganda, podemos observar diferentes traduções da PCD. Em uma propaganda da campanha liderada pela Ordem dos Advogados, Seção de São Paulo (OAB-SP), realizada em 2016, ano que a cidade do Rio de Janeiro sediou os Jogos Paralímpicos, e que teve destaque no jornal Estadão, temos uma tradução do esporte como promotor de inclusão de pessoas com deficiência física. Nessa peça impressa, temos um homem com duas pernas mecânicas, vestido com roupas esportivas e de braços abertos, dando sentido de comemoração, com a seguinte frase: "Inclusão +, com mais respeito a pessoas com deficiência vamos fazer uma Brasil mais justo". A ação tinha como objetivo promover a consciência e respeito à Lei $n^{\circ} 13.146$, afirmando PCD como sujeitos de direitos em uma sociedade inclusiva.

Em sintonia com tal propaganda, temos uma campanha vinculada à Revista Vogue Brasil (2016), desenvolvida com o apoio do comitê Paralímpico Brasileiro, tendo a ação nomeada "Somos todos paralímpicos", no qual os atores globais Cléo Pires e Paulinho Vilhena aparecem como paratletas, ela, com um braço amputado, e ele, com uma perna mecânica. Apesar de a revista e os responsáveis pela campanha afirmarem que o objetivo era dar maior "visibilidade aos paratletas e mostrar relevância para o esporte", houve muita polêmica em relação à peça publicitária. As imagens vinculadas obtiveram um grande número de comentários negativos, como apresentou uma matéria na edição do jornal $O$ Globo, questionando a ausência dos próprios atletas, já que se buscava visibilidade à causa (O GLOBO, 2016).

Tal falta de empoderamento da PCD parece bastante evidente diante da própria existência em si do evento das Paralimpíadas. Separada das Olimpíadas, tal evento acaba sendo menos prestigiado e articulado socialmente. É interessante salientar que a diferença nos desempenhos de atletas paralímpicos não poderia justificar tal quadro de segregação, na medida em que esportes femininos, por exemplo, com desempenhos igualmente diferenciados em relação aos masculinos, participam das Olimpíadas. Desse modo, as Paralímpiadas acabam por não contribuir para o prestigiado quadro de medalhas das Olimpíadas e, consequentemente, parece desvalorizado.

Em sintonia com algumas dessas críticas, Tancy Vista Mavignier (2014), mestre em Comunicação Social, ao analisar dados de pesquisa, argumenta que, por mais que se tenha aumentado o número de textos referentes às pessoas com deficiências nas revistas, ainda são as pessoas sem deficiência que falam pelas e das pessoas com deficiência. Por mais que as matérias tratem sobre o tema PCD, elas não dão voz a quem participa desse grupo.

\section{CONSIDERAÇÕES FINAIS}

Foi nossa pretensão, nesta pesquisa, por meio da Teoria Ator-rede, descrever circuitos em que atuam as redes em torno da PCD, buscando simetria ao examinar os argumentos que despontam, a nosso ver, configurando-se como caixa-cinza. Embora o assunto esteja longe de ser esgotado, encontramos algumas controvérsias que nos chamaram atenção.

No campo do Direito, o Estatuto da Pessoa com Deficiência parece ter sido planejado como um avanço por alguns parlamentares, entretanto, para algumas associações civis que representam a PCD, como o Movimento Contra o Estatuto, esse projeto parece não ter sentido, na medida em que a própria Constituição Federal de 1988 já poderia ser vista como garantia dos respectivos direitos. Além disso, 
analisando a inserção da PCD no mercado de trabalho via cotas, percebemos que ela gera contra-argumentos baseados na noção de meritocracia.

Os veículos adaptados também foram alvo de controvérsias. Os críticos argumentam que eles seriam uma forma de empresas de transportes se eximirem de impostos, como o IPI. No caso dos táxis, encontramos argumentos de que exigências legais poderiam fazer a situação financeira ser insustentável para os taxistas, já que um carro adaptado é cerca de $50 \%$ mais caro.

$\mathrm{Na}$ internet, espaço que tem sido cada vez mais visto como um escape da coerção do chamado "politicamente correto", a mídia internacional tem mostrado o aumento de casos de crimes de ódio contra a PCD. 0 jogo online mais famoso da atualidade, League of Legends, é um dos palcos desse cenário. Deficiências mentais são usadas como piada e xingamento, rasgando o véu de polidez que aparentemente existe nas relações off-line.

Salienta-se que, no momento atual, o governo federal articula a aprovação da reforma da Previdência, que aponta na direção de um significativo impacto para as pessoas com deficiência que dependem do BPC (benefício de prestação continuada). As críticas argumentam que o BPC faz parte da Assistência Social e nada tem a ver com a Previdência, sendo assim, não faria sentido a reforma alterá-lo. Ademais, o valor do BPC está vinculado ao valor do salário mínimo - a proposta do governo defende desvinculá-lo. Mara Gabrilli, deputada federal e cadeirante, argumenta contra essa mudança, afirmando que não tendo um valor mínimo a ser estipulado, os dependentes desse benefício estariam mais vulnerabilizados (LUPION, 2017).

Desse modo, ao adentrarmos em uma região de emaranhadas redes, pudemos rastrear a produção da pessoa com deficiência na atualidade, Tal produção se dá, na atualidade, intensamente mediada pelo Direito, pela grande mídia, pelo "politicamente correto", pelo limite entre humor e crimes de ódio, pela internet, pelo discurso da meritocracia, pelo mundo do entretenimento, pela propaganda, pela literatura, dentre outros. Embora não tenhamos encontrado nenhum argumento diretamente "contra" a PCD, as teses da inclusão e do respeito têm sido postas à prova e encontrado resistências significativas na atualidade. 


\section{REFERÊNCIAS}

ARAÚJO, E. A. B. S.; FERRAZ, F. B. O conceito de pessoa com deficiência e seu impacto nas ações afirmativas brasileiras no mercado de trabalho. Anais do XIX Encontro Nacional do CONPEDI. 2010. Disponível em: <http://www.publicadireito.com.br/conpedi/manaus/arquivos/anais/fortaleza/3348. pdf> Acesso em: 02 ago. 2017.

BINI, F. Tyrion Lannister sob a perspectiva de um anão. Disponível em: <http://www.gameofthronesbr. com/2014/07/tyrion-lannister-sob-a-perspectiva-de-um-anao.html> Acesso em: 10 nov. 2017.

BRASIL. LEI No 13.146. 2015. Disponível em: <http://www.planalto.gov.br/ccivil_03/_ato2015-2018/2015/ lei/l13146.htm> Acesso em: 18 out. 2017.

BRASIL. LEI No 10.754. 2003. Disponível em: <http://www.planalto.gov.br/ccivil_03/leis/2003/L10.754. htm\#art1> Acesso em: 18 out. 2017.

BRASIL. LEI No 8.989. 1994. Disponível em: <http://www.planalto.gov.br/ccivil_03/leis/L8989.htm> Acesso em: 18 out. 2017.

Constituição da República Federativa do Brasil. Brasília, Senado Federal: Centro Gráfıco, 1988.

CABRAL, G. Estatuto gera polêmica entre deficientes e parlamentares. 2011. Disponível em: < http:// gutecabral.blogspot.com.br/2010/08/as-vagas-dos-portadores-de-deficiencia.html> Acesso em: 05 out. 2017.

As vagas dos portadores de deficiência em concurso público e a polêmica sobre a sua percentagem. 2010. Disponível em: <http://gutecabral.blogspot.com.br/2010/08/as-vagas-dosportadores-de deficiencia.html> Acesso em: 05 out. 2017.

CÂMARA NOTÍCIAS. Então em vigor a Lei Brasileira de Inclusão. 2016. Disponível em: <http://www2. camara.leg.br/camaranoticias/noticias/DIREITOS-HUMANOS/502371-EM-VIGOR-DESDE-O-INICIODO-ANO,-LEI-BRASILEIRA-DE-INCLUSAO-JA-RECEBE-CRITICAS.html> Acesso em: 20 ago. 2017.

G1. Lei que garante táxis adaptados para deficientes físicos causa controvérsia. 2015. Disponível em: <http://g1.globo.com/pi/piaui/noticia/2015/03/lei-que-garante-taxis-adaptados-para-deficientesfisicos-causa-controversia.htm> Acesso em: 05 out. 2017.

IVIF. A vantagem de ser autista no League of Legends. In Fórum Comportamento do Jogador. 2017. Disponível em: <https://boards.br.leagueoflegends.com/pt/c/comportamento-do-jogador/PpHE8IpEa-vantagem-de-ser-autista-no-league-of-legends> Acesso em 02 ago. 2017.

LATOUR, B. Reensamblar Lo Social: una introdución a la teoria del actor-red. Buenos Aires: Manantial, 2008.

Ciência em ação: como seguir cientistas e engenheiros sociedade afora. São Paulo: Editora UNESP, 2000.

LEITÃO, T. Acessibilidade é o desafio para deficientes em todo país. 2012. Disponível em: https://exame. abril.com.br/brasil/acessibilidade-e-desafio-para-deficientes-em-todo-o-pais/amp/ > Acesso em: 12 ago. 2017. 
Julio Cesar de Almeida Nobre I Ivanete da Rosa Silva de Oliveira I Nathan da Cunha Gonçalves Joseane de Almeida dos Santos I Camila Fernandes da Silva I Dyene Kelly Leopoldina Rodrigues da Silva

LUPION, B. O que é BPC, um dos itens mais polêmicos da reforma da Previdência. Nexo. 2017. Disponível em: < https://www.nexojornal.com.br/expresso/2017/03/30/0-que-\%C3\%A9-o-BPC-um-dos-itensmais-pol\%C3\%AAmicos-da-reforma-da-Previd\%C3\%AAncia> Acesso em: 10 nov. 2017.

MARSH, S. The culture of hatred for the disabled comes from the top. The Guardian. 2011. Disponível em: <https://www.theguardian.com/commentisfree/2011/sep/16/disabled-hate-crime-governmentbenefits> Acesso em: 16 set. 2017.

MAVIGNIER, T. C. A deficiência física nas revistas Veja, Época e Isto É: um estudo de recepção. 2014. Disponível em: <https://casperlibero.edu.br/wp-content/uploads/2014/04/Tancy-Costa-Mavignier. pdf > Acesso em: 14 out. 2017.

MORTIMER, C. Hate crime against disabled people rises 41 per cent in one year. Independent. 2015. Disponível: <http://www.independent.co.uk/news/uk/hate-crime-against-disabled-people-rises-41per-cent-in-one-year-a6713546.html> Acesso em: 16 set. 2017.

MOURA, J. Estatuto gera polêmica entre deficientes e parlamentares. 2010. Disponível em: < http:// www.jb.com.br/pais/noticias/2007/12/02/estatuto-gera-polemica-entre-deficientes-e-parlamentares> Acesso em: 05 out. 2017.

NOBRE, J. C. A.; PEDRO, R. M. L. R. Reflexões sobre possibilidades metodológicas da Teoria Ator-Rede. Cadernos UniFOA. Volta Redonda, Ano V, n. 14, dezembro 2010. Disponível em: <http://www.unifoa.edu. br/cadernos/edicao/14/47.pdf> Acesso em: 02 ago. 2017.

O GLOBO. Campanha com 'atores paralímpicos' gera polêmica. Cléo Pires se defende. 2016. Disponível em: <https://www.google.com.br/amp/s/oglobo.globo.com/esportes/campanha-com-atores-paralimpicosgera-polemica-cleo-pires-se-defende-19987262\%3Fversao=amp> Acesso em: 10 ago. 2017.

PEREIRA, N. Redes sociais validam o ódio das pessoas, diz psicanalista. [10 de janeiro, 2017]. São Paulo: BBC Brasil. 2017. Disponível em: < http://www.bbc.com/portuguese/brasil-38563773> Acesso em: 18 out. 2017.

PEREIRA, R. Diversidade funcional: a diferença e o histórico modelo de homem-padrão. História, Ciências, Saúde - Manguinhos, Rio de Janeiro, v.16, n.3, jul.set. 2009, p. 715-728. 2006. Disponível em: <http:// www.scielo.br/scielo.php?script=sci_arttext\&pid=S0104-59702009000300009 > Acesso em: 03 ago. 2017.

ROX, M. League of Legends deve lucrar R\$ 5,65 bilhões em 2016, aponta estudo. TecMundo. 2016. Disponível em: <https://www.tecmundo.com.br/esports/110816-league-of-legends-deve-lucrar-r-565-bilhoes-2016-aponta-estudo.htm> Acesso em: 16 set. 2017.

SALGADO, I. M.; VALADARES, E. R. Para compreender a deficiência. Belo Horizonte: Rona Editora, 2000.

SASSAKI, R. K. Inclusão: construindo uma sociedade para todos. Rio de Janeiro: WVA, 2010.

SENADO NOTÍCIAS. Lei Brasileira de Inclusão completa um ano com avanços na educação. 2016. Disponível em: <https://www12.senado.leg.br/noticias/materias/2016/07/01/lei-brasileira-de-inclusaocompleta-um-ano-com-avancos-na-educacao> Acesso em: ago. 2017. 
SERAFIM, I. Campanha de jogos paralímpicos com Cléo Pires e Paulo Vilhena causa polêmica. 2016. Disponível em: <http://emais.estadao.com.br/noticias/moda-beleza,campanha-de-jogos-paralimpicoscom-cleo-pires-e-paulinho-vilhena-causa-polemica-na-internet,10000071682> Acesso em: 12 ago. 2017.

SNOWDON, K. Online Hate Crime To Be Taken As Seriously As Threats Made 'Offline', New CPS Guidelines Recommend. Huffington Post. 2017. Disponível em: <http://huffingtonpost.co.uk/entry/online-hatecrime-seriously-threats-offline-cps_uk_599a899ae4b0e8cc855e6d78> Acesso em: 16 set. 2017.

SOUTO, L. Cresce o número de pessoas com deficiência no mercado, mas preconceito resiste. O Globo. 2016. Disponível em: <http://oglobo.globo.com/sociedade/cresce-numero-de-pessoas-com-deficienciano-mercado-mas-preconceito-persiste-20128635> Acesso em: 18 out. 2017.

SOUZA, L. A. V. Campanha da OAB SP usa o futebol para defender a inclusão. 2016. Disponível em: <https://www.google.com.br/amp/brasil.estadao.com.br/blogs/vencer-limites/campanha-da-oab-spusa-o-futebol-para-defender-a-inclusao/\%3famp> Acesso em: 20 ago. 2017.

THOMÉ, C. No País, $77 \%$ dos portadores de deficiência se sentem discriminados. 0 Estado de São Paulo. 2010. Disponível: < http://www.estadao.com.br/noticias/geral,no-pais-77-dos-portadores-dedeficiencia-se-sentem-desrespeitados-imp-,653356> Acesso em: 18 out. 2017.

VOGUE BRASIL. Somos Todos Paralímpicos: a campanha com Cleo Pires e Paulinho Vilhena. 2016. Disponível em: <http://vogue.globo.com/moda/moda-news/noticia/2016/08/somos-todos-paralimpicoscampanha-com-cleo-pires-e-paulinho-vilhena.html> Acesso em: 20 ago. 2017. 